\title{
Work stress in aircraft maintenance technicians: The role of work- life balance
}

\author{
Cucunda Resi Anggarini, Indrayanti \\ Faculty of Psychology, Universitas Gadjah Mada, Indonesia \\ Corresponding author: cucunda.resi.a@ugm.mail.ac.id
}

\section{ARTICLE INFO}

Article history

Received July 17, 2020

Revised January 14, 2021

Accepted January 14, 2021

Keywords

aircraft maintenance technician; personal life interfere work; work interfere personal life; work-life balance; work stress.

\begin{abstract}
Work stress is a widespread issue among various kinds of employees because of its negative impact. This study aimed to determine the role of work-life balance toward work stress experienced by aircraft maintenance technicians. A total of ninety-two aircraft maintenance technicians participated in this quantitative approach using scales as the research instrument. The data were collected and then analyzed using multiple linear regression methods. The results showed that three dimensions of work-life balance, namely WIPL, PLIW, and WPLE, have a significant simultaneous role on work stress with an effective contribution of $56.5 \%$. Partially, WIPL and PLIW significantly have a positive role on work stress with a contribution of $40.7 \%$ and $12.19 \%$, whereas WPLE does not have a significant role on work stress. This study implies that a low level of WIPL and PLIW will reduce work stress levels in aircraft maintenance technicians and vice versa. Therefore, organizations can support aircraft maintenance technicians in managing work-life balance to maintain work stress levels.
\end{abstract}

\section{Introduction}

Work stress is a phenomenon that attracts the attention of various parties. So far, work stress has been noted as the most serious problem for employees globally (Amalina et al., 2016). In 2012, the Chief Financial Officer of Innovation surveyed work stress in the Asia Pacific region and reported that Indonesia's work stress level reached 73\% (CFO, 2012). The survey shows that Indonesia experienced a decrease in work stress levels by $7.6 \%$ in seven years. Nevertheless, this percentage is still higher than the average global level of work stress at $62 \%$.

Parker and DeCotiis (1983) define work stress as a feeling toward disrupting an individual's normal functioning at work. This definition of work stress can be classified into two dimensions, namely time stress and anxiety. Time stress describes as the feelings experienced being under considerable time pressure, while anxiety refers to feelings of anxiety related to work that occurs in individuals. Work stress is also defined as a process when the work environment is full of pressures that require employees to respond adaptively to these conditions (Jex \& Britt, 2008). According to Robbins and Judge (2013), work stress can occur when employees face various uncertain conditions in the work environment.

Work stress can negatively impact the physical and psychological conditions of employees (Dessler, 2014; Riggio, 2003). It can also lead to actions that might hamper organizational productivity, such as low employee performance, high absenteeism, and high turnover rate (Riggio, 2003). From the organizational side, work stress could be financially 
disadvantageous due to the costs incurred for health care because of work-related stress (Jex $\&$ Britt, 2008). Although work stress is commonly discussed in a negative context, it also has a positive impact. Employees can turn work stress into potential gains by using it positively to perform at their limit (Robbins \& Judge, 2013).

Employees can experience work stress with various types of jobs, such as the banking sector (Karkoulian et al., 2016), prison officers (Armstrong et al., 2015), and aircraft maintenance technicians (Chang \& Wang, 2010). According to Yazgan and Kavsaoğlu (2017), working as an aircraft maintenance technician is a type of "stressful task" related to time, facilities, environment, procedures, to supervision. Also, aircraft maintenance technicians have a crucial role in ensuring aircraft's airworthiness. The main role includes assessing, classification, and treating problems that can threaten aircraft's airworthiness (Pettersen \& Aase, 2008).

The demand for aircraft technicians continues to increase along with the increasing use of aircraft for domestic transportation. Air transportation statistical data from 2017 shows that the number of passengers using planes is increasing by 23\% (BPS, 2017). This increase is assumed to be caused by the public's assumption that aircraft are efficient means of safetyprioritizing transportation (IATA, 2016). However, based on the 2016 National Transportation Safety Committee report, there were still cases of aircraft accidents from 2010 to 2016 (KNKT, 2016). Aviation Safety Network also explained that from 2012 to 2018, there had been an increase in the number of aircraft accidents with an increasing number of victims (ASN, 2019). In this situation, an aircraft technician's job plays an essential role in decreasing aircraft accidents. Work stress is one of the risk factors for low performance, which can impact the technicians' error in maintaining aircraft (Chang \& Wang, 2010). The Federal Aviation Administration identifies poor aircraft maintenance as one of the leading causes of aviation accidents (Fogarty, 2004). Therefore, organizations need to maintain the technicians' conditions as not to experience stress or pressures that can potentially lead to work errors.

An aircraft maintenance technician is a job prone to work-related stress because of time pressure and minimal work control (Fogarty, 2004; Yazgan \& Kavsaoğlu, 2017). This job also involves facing hazardous environments and stressors that can induce work stress that would affect work quality (Aamodt, 2013; Kim \& Song, 2015). The aviation industry's condition that operates 24 hours nonstop requires technicians to have a tight work schedule, so they have to work with shift systems and limited rest periods (Purnell et al., 2002; Wang et al., 2016). According to Lac and Chamoux (2004), abnormal working times such as shift systems can negatively impact employees. It can affect social functions, including personal life, and interfere with it, increasing work stress (Greenhaus et al., 2003). The technician's work stress is also significantly related to the low performance in performing aircraft maintenance (Wang et al., 2016; Yazgan \& Kavsaoğlu, 2017).

Robbins \& Judge (2013) describe three factors that cause work stress: personal factors, environmental factors, and organizational factors. One of the causes of work stress originating from organizational factors is inadequate work-life balance (Babatunde, 2013; Hobson et al., 2001; Jex \& Britt, 2008). Specifically, Wang et al. (2016) state that work-related stress experienced by aircraft maintenance technicians can be caused by work schedules that are not conducive to achieving work-life balance. Furthermore, Alali et al. (2018) state that there are correlations between employee health, work shift, work stress, and work-life balance.

Work-life balance has significant work-related stress roles (Armstrong et al., 2015; Karkoulian et al., 2016; Rabenu et al., 2017). The work-life balance that is not achieved can result in the employees' work stress (Atheya \& Arora, 2014). Aircraft maintenance technicians who have difficulty achieving work-life balance can face role overload and role conflict that significantly contribute to high work stress levels (Tourigny et al., 2010). Therefore, work-life balance is discussed in this study, considering that employees have the responsibility in balancing work and life outside of work so that employees can manage work stress levels (Jex \& Britt, 2008). 
Fisher (2001) states that the concept of work-life balance can be seen based on the components of time, behavior, tension, and energy balanced between the demands of roles in work and personal life. Work-life balance is defined as an individual's perception that activities at work and outside of work run harmoniously and by the priorities they have at the moment (Kalliath \& Brough, 2008). According to Greenhaus et al. (2003), these conditions can be achieved if the individual is involved and has a balanced satisfaction between their roles in work and personal life. Brough et al. (2014) also stated that the term 'work-life balance' is generally used for individuals who desire to balance other activities outside of work such as exercising, studying, and going on vacations.

Fisher (2001) also revealed that work-life balance consists of three dimensions which include work interfere personal life (WIPL), personal life interfere work (PLIW), and work personal life enhancement (WPLE). WIPL is a dimension that measures the extent to which work has a negative influence on one's personal life (Nohe et al., 2015). WIPL happens whenever someone's personal life is interrupted because of work. Meanwhile, the PLIW dimension measures the extent to which a person's personal life has a negative impact on work (Nohe et al., 2015). For example, a person is too tired to ignore work because of the things happening in their personal life. The next dimension is WPLE that measures the extent to which a person's personal life is improved by work or vice versa (Fisher, 2001). This dimension describes the extent to which work and personal life enhance each other.

Individuals who have more than one role in their life can experience interference with their roles that cause work to interfere with personal life and vice versa (Frone, 2000). It can also cause individuals to experience difficulties in fulfilling their roles. Fisher et al. (2009) explain that managing various roles can lead to WIPL and PLIW, which can impact work stress. Nevertheless, employee participation in work and life outside of work can increase WPLE, which is associated with positive consequences for employees, such as decreased work stress levels (Hanson et al., 2006).

This research will also discuss WIPL and PLIW, which are significantly correlated with work stress (Allen et al., 2000; Nohe et al., 2015, Major et al., 2002). Individuals who have high integration between work and personal life can blur or even eliminate the boundaries between the two roles (Abhyankar \& Pujari, 2012). However, WPLE is evidence that various roles in life can facilitate each other to positively impact work performance (Hanson et al., 2006). Grzywacz and Marks (2000) also revealed that WPLE could improve employees' well-being and mental health.

The influence of work-life balance on work stress, as described in previous studies, can be used by organizations to achieve work-life balance so that employees can perform their best at work. However, the research on work stress and work-life balance, especially for aircraft maintenance technicians, is still limited. Therefore, this study was conducted to determine the role of work-life balance on work stress in aircraft maintenance technicians. This study's hypothesis is that the three dimensions of work-life balance, namely WIPL, PLIW, and WPLE, simultaneously have roles toward work stress. WIPL and PLIW have positive roles toward work stress, whereas WPLE has a negative role toward work stress.

\section{Method}

\section{Research Design}

A quantitative approach was used in this study using a scale as the research instrument. The data collection procedure was carried out using a questionnaire given to subjects through the related organizations. 


\section{Participants}

Participants involved in this study were employees who work as an aircraft maintenance technician. Of 92 technicians in this study, 79 were male $(85.87 \%)$, while 13 were female (14.13\%). Their age ranges from 22 to 54 years old. The predominant age range was 26-29 $(33.7 \%)$, while the age range with the lowest number of subjects was 30-33 (17.39\%). 68 subjects $(73.91 \%)$ are married, while 24 subjects $(26.09 \%)$ are not married. The majority of the technicians' tenure ranges from 6-10 years (43.48\%). Most technicians have a vocational or high school educational background $(53.26 \%)$.

\section{Instrument}

The scale used to measure work stress in this study adapted the measuring instrument compiled by Parker and DeCotiis (1983). This scale consists of 11 favorable items that measure two dimensions, namely time stress and anxiety. A sample item of the time stress dimension is "Working here leaves little time for other activities." An example of the anxiety dimension item is "I have felt fidgety or nervous as a result of my job." All items on this scale use a Likert model with five alternative answers consisting of Strongly Disagree, Disagree, Neutral, Agree, and Strongly Agree, representing a scale of 1 to 5, respectively. The higher the score obtained by the subject indicates a higher level of work stress, whereas if the score obtained is lower, then the level of work stress is also lower. Alpha Cronbach reliability and item discrimination index of the work stress scale is shown in Table 1.

This research refers to the concept of work-life balance by Fisher (2001), adapted into Bahasa Indonesia. The scale is a multidimensional construct because the work-life balance in this study is composed of three dimensions, namely Personal Life Interfere Work (WIPL), Personal Life Interfere Work (PLIW), and Work/Personal Life Enhancement (WPLE). One example of an item rating WIPL is "I am happy with the amount of time I spend doing activities not related to work." PLIW is rated with items such as "My personal life drains me of the energy I need to do my job." Meanwhile, WPLE is rated with items such as " 1 am in a better mood at work because of everything I have going for me in my personal life." The work-life balance scale consists of 20 items with 18 favorable items and two unfavorable items. This scale uses a Likert model with five alternative answers: Never, Rarely, Sometimes, Often, and Always, representing a scale of 1 to 5. The higher scores obtained on the dimensions of WIPL and PLIW indicate lower levels of work-life balance. If the WIPL and PLIW dimensions obtained scores are lower, the level of work-life balance would be higher. Meanwhile, the higher the WPLE dimension score obtained, the higher the work-life balance level and vice versa. Alpha Cronbach reliability and item discrimination index of the work-life balance scale is shown in Table 1.

Table 1

Result of Internal Consistency Test

\begin{tabular}{ccccc}
\hline Variable & Dimension & Number of items & $\begin{array}{c}\text { Item-Total } \\
\text { Correlation }\end{array}$ & $\begin{array}{c}\text { Alpha Cronbach } \\
(\alpha)\end{array}$ \\
\hline \multirow{2}{*}{ Work Stress } & Time stress & 7 & $.368-.810$ & .913 \\
& Anxiety & 4 & $.264-.705$ & .837 \\
\multirow{3}{*}{ Work-Life Balance } & WIPL & 11 & $.556-.680$ & .816 \\
& PLIW & 5 & $.423-.632$ & .707 \\
\hline
\end{tabular}




\section{Data analysis}

A multiple linear regression method is used to determine how much the independent variable's contribution to the dependent variable. Multiple linear regression is carried out by considering that the three dimensions of the work-life balance variable will simultaneously and partially influence the work stress variable. Data analysis in this study was conducted using SPSS version 21 for Windows.

\section{Results}

Hypothesis testing is conducted using multiple linear regression analysis to determine the role of work-life balance on work stress. This research involved the three dimensions of work-life balance in the analysis to see the roles of WIPL, PLIW, and WPLE simultaneously toward work stress in aircraft maintenance technicians.

Table 2

\begin{tabular}{cccc}
\hline$R$ & $R$ Square & $F$ & Sig. \\
\hline .752 & .565 & 38.135 & .000 \\
\hline
\end{tabular}

Table 2 shows the values from multiple linear regression analysis where $F=38.135$ with a significance level of $p=.000$. This result indicates that the hypothesis stating that the three dimensions of work-life balance simultaneously have a role toward work stress is accepted. The results of multiple linear regression analysis indicate that WIPL, PLIW, and WPLE generate $R^{2}=.565$. Therefore, the three dimensions of work-life balance simultaneously provide an effective contribution by $56.5 \%$ to work stress.

Table 3 below shows that partially, WIPL and PLIW have a significant positive impact on work stress with a contribution of $40.7 \%$ and $12.9 \%$. Meanwhile, WPLE has no significant influence on work stress in aircraft maintenance technicians.

Table 3

The Role of Each Work-Life Balance Dimensions on Work Stress

\begin{tabular}{ccccc}
\hline Dimension & Beta & $t$ & Sig. & $\begin{array}{c}\text { Effective } \\
\text { contribution (\%) }\end{array}$ \\
\hline WIPL & .578 & 7.345 & .000 & 40.7 \\
PLIW & .246 & 3.108 & .003 & 12.9 \\
WPLE & -.116 & -1.609 & .111 & 2.9 \\
\hline
\end{tabular}
follows:

Based on Table 3, we can determine the regression equation formula in this study as

$$
\text { Work Stress }=.578(\text { WIPL })+.246(\text { PLIW })-.116(\text { WPLE })
$$

The regression coefficient's value on the WIPL dimension is .578, which means that each increase in WIPL will increase work stress levels by .578, assuming that the other dimensions of work-life balance are fixed. Furthermore, the regression coefficient on the PLIW dimension is .246, which means that each increase in PLIW will increase work stress levels by .246, assuming that the other dimensions of work-life balance are fixed. In the WPLE dimension, the regression coefficient is -.116. Increasing WPLE will increase work stress levels by -.116, assuming that the other work-life balance dimensions are fixed. 


\section{Discussion}

The results of this study indicate that there is a significant simultaneous role of three types of work-life balance toward work stress in aircraft maintenance technicians with a contribution of $56.5 \%$. These findings are in line with a study conducted by Hobson et al. (2001) that problems related to work-life balance can significantly cause work stress. Employees' inability to achieve work-life balance or manage demands in work and personal life in a balanced manner is one of the factors causing work stress (Riggio, 2003). Babatunde (2013) also stated that not achieving a work-life balance is associated with high work stress levels on employees. Besides, a low level of work-life balance also leads to higher work stress (Brough et al., 2014) and a dysfunctional effect on well-being to various other aspects of employee life (Allen et al., 2000).

Atheya and Arora (2014) revealed that work-life balance negatively affects work stress. Work-life balance significantly contributes negatively to work stress with a contribution of $55 \%$ (Bell et al., 2012) and 25\% (Razak et al., 2014). This study's results indicate a contribution of $56.5 \%$, which means the results of this study strengthen the existing empirical evidence further.

Parkes and Langford (2008) explain that a work-life balance that is not achieved can increase employees' work stress levels. Among aircraft maintenance technicians, workrelated stress can be caused by work schedules that are not conducive to achieving work-life balance (Wang et al., 2016). Previous research by Tourigny et al. (2010) conducted in the aviation industry, including aircraft maintenance technicians, also showed that employees who work in abnormal schedules report more disruption to life outside of work, impacting work stress.

This study's main finding reveals that WIPL has a significant positive role on work stress, with a contribution of $40.7 \%$, reflects that the higher levels of WIPL lead to a higher level of work stress experienced by aircraft maintenance technicians. WIPL has a strong correlation with work-related stress (Amstad et al., 2011; Nohe et al., 2015). Major et al. (2002) also revealed that WIPL has a positive and significant relationship with stress in employees due to workload and pressure to work for long periods, which can also happen to aircraft maintenance technicians (Yazgan \& Kavsaoğlu, 2017). Employees must use the time allocated for personal life to meet work demands because of long working hours and lack of control over work schedules related to difficulties in achieving work-life balance (Abhyankar \& Pujari, 2012). According to Lac and Chamoux (2004), aircraft maintenance technicians can also experience this condition due to work conditions that do not support work-life balance, causing work stress.

This study also shows that WIPL has the highest contribution to work stress in aircraft maintenance technicians rather than PLIW and WPLE. Thus, if an aircraft maintenance technician experiencing work interfere personal life, then the level of work stress will increase. Although the three dimensions of work-life balance contribute to work stress, WIPL has a stronger role than PLIW and WPLE (Steenbergen et al., 2007). This result supports the finding of Grzywacz and Marks (2000), which reveals that WIPL is experienced more frequently than PLIW and WPLE. Balkan (2014) also stated that the contribution of WIPL is higher than the contribution made by PLIW on work stress.

This study also found that PLIW has a significant positive role in aircraft maintenance technicians' work stress with a contribution of $12.9 \%$. It describes that the higher the level of PLIW, the higher the level of work stress experienced by aircraft maintenance technicians. This finding is in line with Fisher et al. (2009), which state that PLIW can affect work stress. This finding also supports previous research showing that PLIW has a significant positive contribution to work stress (Balkan, 2014).

However, this study also discovered that WPLE has no significant effect on work stress experienced by aircraft maintenance technicians. This result is not consistent with previous 
findings that state that WPLE is related to employees' work stress (Fisher et al., 2009; Hansson et al., 2001). Jaga and Bagraim (2011) also stated that WPLE could occur because one role can be beneficial for another role. Still, it must be mutually enhancing in the implementation of the role carried out by the employee. For employees who have more than one role, disruptions between work-life and personal life still need to be managed.

This study implies that work-life balance, as composed of three dimensions, could predict work stress among aircraft maintenance technicians. As the highest contributor to work stress, WIPL has the strongest implication. Aircraft maintenance technicians also need to manage personal life interfere work, leading to work-life balance such as childcare, eldercare, or marital relationships (Voydanoff, 2004). Also, maintain other non-family roles outside work such as sports, study, and travel (Kalliath \& Brough, 2008) to maintain manageable levels of work stress.

This study's results are expected to be a consideration for organizations in formulating a decision to support the achievement of work-life balance, especially in the aircraft maintenance technicians' related policies. The organizations can recommend programs that support aircraft maintenance technicians in managing work-life balance. With the strongest impact, the organizations can also improve the effectiveness of work-life balance practice to manage WIPL to reduce work stress levels. This study's limitation is that only a small number of technicians participated and the data obtained only focus on one aircraft maintenance organization in Indonesia. Hence, data involving other aircraft maintenance organizations can be considered in future research so that the research results can be broadly generalized.

\section{Conclusion}

This study concluded that aircraft maintenance technicians' level of work stress was influenced by the three dimensions of work-life balance, namely WIPL, PLIW, and WPLE. Partially, a high level of WIPL and PLIW will increase the work stress levels on aircraft maintenance technicians and vice versa. Meanwhile, WPLE does not affect work stress. The findings indicate that WIPL has a stronger effect on work stress in aircraft maintenance technicians than the PLIW and WPLE.

\section{References}

Aamodt, M. G. (2013). Industrial/organizational psychology: An applied approach. Cengage Learning.

Abhyankar, S., \& Pujari, U. (2012). Occupational stress and work-life imbalance among industrial employees. Journal of Psychosocial Research, 7(1), 17.

Alali, H., Braeckman, L., Van Hecke, T., \& Wahab, M. A. (2018). Shift work and occupational accident absence in Belgium: Findings from the sixth European working condition survey. International Journal of Environmental Research and Public Health, 15(9), 1-13. https://doi.org/10.3390/ijerph15091811

Allen, T. D., Herst, D. E., Bruck, C. S., \& Sutton, M. (2000). Consequences associated with work-to-family conflict: A review and agenda for future research. Journal of Occupational Health Psychology, 5(2), 278-308. https://doi.org/10.1037/10768998.5.2.278

Amalina, M. Z., Huda, B. Z., \& Hejar, A. R. (2016). Job stress and its determinants among academic staff in a university in Klang Valley Malaysia. International Journal of Public Health and Clinical Sciences, 3(6), 125-136.

Amstad, F. T., Meier, L. L., Fasel, U., Elfering, A., \& Semmer, N. K. (2011). A meta- 
analysis of work-family conflict and various outcomes with a special emphasis on cross-domain versus matching-domain relations. Journal of Occupational Health Psychology, 16(2), 151-169. https://doi.org/10.1037/a0022170

Armstrong, G. S., Atkin-Plunk, C. A., \& Wells, J. (2015). The relationship between workfamily conflict, correctional officer job stress, and job satisfaction. Criminal Justice and Behavior, 42(10), 1066-1082. https://doi.org/10.1177/0093854815582221

ASN. (2019). Fatal accidents and fatalities per year for airliner. Retrieved from https://aviation-safety.net/statistics/period/stats.php?cat=A1

Atheya, R., \& Arora, D. R. (2014). Stress and its brunt on employee's work-life balance: A conceptual study. Journal of Humanities and Social Science, 19(3), 57-62. https://doi.org/10.9790/0837-19355762

Babatunde, A. (2013). Occupational stress: A review on conceptualizations, causes and cure. Economic Insights-Trends \& Challenges, 65(3), 73-80.

Balkan, O. (2014). Work-life balance, job stress and individual performance: An application. International Journal of Management Sciences and Business Research, 3(3), 38-46.

Bell, A. S., Rajendran, D., \& Theiler, S. (2012). Job stress, well-being, work-life balance and work-life conflict among Australian academics. Journal of Applied Psychology, 8(1), 25-37. https://doi.org/10.7790/ejap.v8i1.320

BPS. (2017). Air transportation statistics. Badan Pusat Statistika. Retrieved from https://www.bps.go.id/publication/2018/11/27/c5a66561bc763984bed341db/statistiktransportasi-udara-2017.html

Brough, P., Timms, C., O’Driscoll, M. P., Kalliath, T., Siu, O. L., Sit, C., \& Lo, D. (2014). Work-life balance: A longitudinal evaluation of a new measure across Australia and New Zealand workers. International Journal of Human Resource Management, 25(19), 2724-2744. https://doi.org/10.1080/09585192.2014.899262

CFO. (2012). Work is top trigger of stress for Asia-Pasific workers. Retrieved from https://www.cfoinnovation.com/work-top-trigger-stress-for-asia-pacific-workers

Chang, Y. H., \& Wang, Y. C. (2010). Significant human risk factors in aircraft maintenance technicians. Journal of Safety Science, 48(1), 54-62. https://doi.org/10.1016/j.ssci.2009.05.004

Dessler, G. (2014). Fundamentals of human resource management. Pearson Education Limited.

Fisher, G. G. (2001). Work/personal life balance: A construct development study. (PhD thesis). Bowling Green State University, Ohio.

Fisher, G. G., Bulger, C. A., \& Smith, C. S. (2009). Beyond work and family: A measure of work/nonwork interference and enhancement. Journal of Occupational Health Psychology, 14(4), 441-456. https://doi.org/10.1037/a0016737

Fogarty, G. (2004). The role of organizational and individual differences variables in aircraft maintenance performance. International Journal of Applied Aviation Studies, 4(3), 7390.

Frone, M. R. (2000). Handbook of occupational health psychology: Work-family balance. American Psychological Association.

Greenhaus, J. H., Collins, K. M., \& Shaw, J. D. (2003). The relation between work-family balance and quality of life. Journal of Vocational Behavior, 63(3), 510-531. https://doi.org/10.1016/S0001-8791(02)00042-8

Grzywacz, J. G., \& Marks, N. F. (2000). Reconceptualizing the work-family interface: An ecological perspective on the correlates of positive and negative spillover between work and family. Journal of Occupational Health Psychology, 5(1), 111-126. https://doi.org/10.1037/1076-8998.5.1.111

Hanson, G. C., Hammer, L. B., \& Colton, C. L. (2006). Development and validation of a 
multidimensional scale of perceived work-family positive spillover. Journal of Occupational Health Psychology, 11(3), 249-265. https://doi.org/10.1037/10768998.11.3.249

Hansson, R. O., Robson, S. M., \& Limas, M. J. (2001). Stress and coping among older workers. Work, 17(3), 247-256.

Hobson, C. J., Delunas, L., \& Kesic, D. (2001). Compelling evidence of the need for corporate work/life balance initiatives: Results from a national survey of stressful lifeevents. Journal of Employment Counseling, 38(3), 38-44. https://doi.org/10.1002/j.2161-1920.2001.tb00491.x

IATA. (2016). Robust passenger demand continues. IATA Press Release. Retrieved from https://www.iata.org/pressroom/pr/Pages/2015-09-04-02.aspx

Jaga, A., \& Bagraim, J. (2011). The relationship between work-family enrichment and workfamily satisfaction outcomes. South African Journal of Psychology, 41(1), 52-62. https://doi.org/10.1177/008124631104100106

Jex, S. M., \& Britt, T. W. (2008). Organizational psychology: A scientist-practitioner approach. John Wiley \& Sons.

Kalliath, T., \& Brough, P. (2008). Work-life balance: A review of the meaning of the balance construct. Journal of Management \& Organization, 14(3), 323-327. https://doi.org/10.1017/s1833367200003308

Karkoulian, S., Srour, J., \& Sinan, T. (2016). A gender perspective on work-life balance, perceived stress, and locus of control. Journal of Business Research, 69(11), 49184923. https://doi.org/10.1016/j.jbusres.2016.04.053

Kim, C. Y., \& Song, B. H. (2015). A study on safety culture in aviation maintenance organization. Advanced Science and Technology Letters, 120, 485-490.

KNKT. (2016). Data investigasi kecelakaan penerbangan (Flight accident investigation data). Media Release KNKT. Retrieved from http://knkt.dephub.go.id/knkt/ntsc_home/Media_Release/Media Release KNKT 2016/Media Release 2016 - IK Penerbangan 20161130.pdf

Lac, G., \& Chamoux, A. (2004). Biological and psychological responses to two rapid shiftwork schedules. Ergonomics, 47(12), 1339-1349. https://doi.org/10.1080/00140130410001724237

Major, V. S., Klein, K. J., \& Ehrhart, M. G. (2002). Work time, work interference with family, and psychological distress. Journal of Applied Psychology, 87(3), 427-436. https://doi.org/10.1037/0021-9010.87.3.427

Nohe, C., Meier, L. L., Sonntag, K., \& Michel, A. (2015). The chicken or the egg? A metaanalysis of panel studies of the relationship between work-family conflict and strain. Journal of Applied Psychology, 100(2), 522-536. https://doi.org/10.1037/a0038012

Parker, D. F., \& DeCotiis, T. A. (1983). Organizational determinants of job stress. Organizational Behavior and Human Performance, 32(2), 160-177. https://doi.org/10.1016/0030-5073(83)90145-9

Parkes, L. P., \& Langford, P. H. (2008). Work-life balance or work-life alignment? A test of the importance of work-life balance for employee engagement and intention to stay in organizations. Journal of Management and Organization, 14(3), 267-284. https://doi.org/10.5172/jmo.837.14.3.267

Pettersen, K. A., \& Aase, K. (2008). Explaining safe work practices in aviation line maintenance. Safety Science, 46(3), 510-519. https://doi.org/10.1016/j.ssci.2007.06.020

Purnell, M. T., Feyer, A. M., \& Herbison, G. P. (2002). The impact of a nap opportunity during the night shift on the performance and alertness of 12-h shift workers. Journal of Sleep Research, 11(3), 219-227. https://doi.org/10.1046/j.1365-2869.2002.00309.x 
Rabenu, E., Tziner, A., \& Sharoni, G. (2017). The relationship between work-family conflict, stress, and work attitudes in. International Journal of Manpower, 38(8), 11431156. https://doi.org/10.1108/IJM-01-2014-0014

Razak, M. I., Yusof, N. M., Azidin, R. A., Abdul Latif, M. M. R., \& Ismail, I. (2014). The impact of work stress towards work-life balance in Malaysia. International Journal of Economics, Commerce and Management, II(11), 1-16.

Riggio, R. E. (2003). Introduction to industrial/organizational psychology. Prentice Hall.

Robbins, S. P., \& Judge, T. A. (2013). Organizational behavior. Pearson Education.

Steenbergen, E. F., Ellemers, N., \& Mooijaart, A. (2007). How work and family can facilitate each other: Distinct types of work-family facilitation and outcomes for women and men. Journal of Occupational Health Psychology, 12(3), 279-300. https://doi.org/10.1037/1076-8998.12.3.279

Tourigny, L., Baba, V. V., \& Wang, X. (2010). Stress episode in aviation: The case of China. Cross Cultural Management, 62-78. https://doi.org/10.1108/13527601011016916

Voydanoff, P. (2004). Implications of work and community demands and resources for work-to-family conflict and facilitation. Journal of Occupational Health Psychology, 9(4), 275-285. https://doi.org/10.1037/1076-8998.9.4.275

Wang, Y., Keller, J. C., Huang, C., \& Fanjoy, R. O. (2016). An exploratory study: Correlations between occupational stressors, coping mechanisms, and job performance among Chinese aviation maintenance technicians. Journal of Aviation Technology and Engineering, 5(2), 69-80. https://doi.org/10.7771/2159-6670.1129

Yazgan, E., \& Kavsaoğlu, M. Ş. (2017). Evaluation of stress affecting aircraft maintenance technician's performance. International Journal of Computing, Communication and Instrumentation Engineering, 4(1), 96-101. 